\title{
Dynamical Mechanism for the Increase in Tropical Upwelling in the Lowermost Tropical Stratosphere during Warm ENSO Events
}

\author{
N. CALvo \\ Atmospheric Chemistry Division, NCAR,* Boulder, Colorado, and Departamento de Física de la Tierra II, \\ Universidad Complutense de Madrid, Madrid, Spain \\ R. R. GARCIA, W. J. RANDEL, AND D. R. MARSH \\ Atmospheric Chemistry Division, NCAR,* Boulder, Colorado
}

(Manuscript received 31 December 2009, in final form 9 March 2010)

\begin{abstract}
The Brewer-Dobson circulation strengthens in the lowermost tropical stratosphere during warm El NiñoSouthern Oscillation (ENSO) events. Dynamical analyses using the most recent version of the Whole Atmosphere Community Climate Model show that this is due mainly to anomalous forcing by orographic gravity waves, which maximizes in the Northern Hemisphere subtropics between 18 and $22 \mathrm{~km}$, especially during the strongest warm ENSO episodes. Anomalies in the meridional gradient of temperature in the upper troposphere and lower stratosphere (UTLS) are produced during warm ENSO events, accompanied by anomalies in the location and intensity of the subtropical jets. This anomalous wind pattern alters the propagation and dissipation of the parameterized gravity waves, which ultimately force increases in tropical upwelling in the lowermost stratosphere. During cold ENSO events a similar signal, but of opposite sign, is present in the model simulations. The signals in ozone and water vapor produced by ENSO events in the UTLS are also investigated.
\end{abstract}

\section{Introduction}

El Niño-Southern Oscillation (ENSO) is the largest source of interannual variability in the tropical troposphere. Some studies have documented the propagation of the ENSO signal to the stratosphere (Calvo Fernandez et al. 2004; Sassi et al. 2004; García-Herrera et al. 2006; Manzini et al. 2006), mainly at middle and high latitudes, where ENSO is able to modify the stratospheric mean meridional circulation, also known as Brewer-Dobson (BD) circulation. These works have shown that during a strong warm ENSO event, anomalous upward propagation and dissipation of planetary waves at middle and high latitudes leads to the acceleration of the stratospheric

* The National Center for Atmospheric Research is sponsored by the National Science Foundation.

Corresponding author address: Natalia Calvo, Atmospheric Chemistry Division, National Center for Atmospheric Research, P.O. Box 3000, Boulder, CO 80307.

E-mail: calvo@ucar.edu branch of the BD circulation, resulting in a warmer polar stratosphere and a weaker polar vortex. In the tropics, Marsh and Garcia (2007) showed that there is a strong correlation, maximizing at a lag of 4-5 months, between the Niño 3.4 index (N3.4) and temperature, ozone, and vertical velocity in the lower stratosphere. Garcia and Randel (2008) studied the acceleration of the BD circulation in the tropical lowermost stratosphere as greenhouse gas (GHG) concentrations increase in past and future simulations of the Whole Atmosphere Community Climate Model (WACCM). They showed that the acceleration occurs as a result of an enhancement in explicitly resolved wave forcing in the subtropics. Garcia and Randel also noted that the BD circulation strengthened during warm ENSO events and suggested that the same mechanism might act during these events as under increasing concentrations of GHG. Very recently, Randel et al. (2009) showed a coherent ENSO signal in temperature and ozone in the tropical upper troposphere and lower stratosphere (UTLS) in observations and in the most recent version of WACCM, which includes two additional sources of variability important in the tropics: 
the quasi-biennial oscillation (QBO) and volcanic eruptions. Their results were consistent with enhanced tropical upwelling during warm ENSO events.

In the present study, we make use of the same WACCM simulations employed by Randel et al. (2009) to explore the dynamical mechanisms whereby ENSO intensifies the BD circulation in the lower tropical stratosphere during its warm (El Niño) phase. We also investigate the behavior during the cold (La Niña) phase to ascertain, in particular, whether tropical upwelling weakens during cold ENSO events.

\section{Model, simulations, and analysis}

WACCM is a fully interactive chemistry-climate model (CCM) that spans the range of altitude from the surface to approximately $140 \mathrm{~km}$. It is based on the version 3 of Community Atmospheric Model (CAM) and incorporates most of the new physical and chemical processes required to model the middle atmosphere, including the mesosphere and lower thermosphere. A detailed description of the base model, WACCM3, can be found in Garcia et al. (2007). In this study we use an updated version of WACCM3 that differs from the model described by Garcia et al. in several important respects: a QBO is imposed by relaxing the winds to observations in the tropics (Matthes et al. 2004), heating from volcanic aerosols is now computed (Tilmes et al. 2009), and gravity waves due to convective and frontal sources are parameterized based on the occurrence of convection and the diagnosis of regions of frontogenesis in the model (Richter et al. 2010). The orographic gravity wave parameterization of McFarlane (1987) is retained unchanged from WACCM3.

For the present study, we have used a four-member ensemble of simulations run at horizontal resolution of $1.9^{\circ}$ latitude by $2.5^{\circ}$ longitude from 1953 to 2006 . Sea surface temperatures (SSTs) and loadings of GHG and halogen species are prescribed from observations, as in Garcia et al. (2007). The simulation is part of the second CCM validation activity (CCMVal2) of the Stratospheric Processes and Their Role in Climate (SPARC) project.

Monthly-mean ensemble series were deseasonalized and then regressed onto different predictors using multivariate linear regression, including terms to account for the long-term trend, the 11-yr solar cycle, the QBO, and the effects of volcanic eruptions. Long-term trends are computed using a linear trend, the solar f10.7 radio flux has been used as a predictor for the 11-yr solar cycle, and the QBO variability has been extracted using two orthogonal time series, as in Randel and Wu (1996). Volcanic effects are represented in terms of an aerosol optical depth (AOD) index, as in Calvo Fernandez et al.
TABLE 1. Month 0 and its corresponding N3.4 value for the strongest warm and cold ENSO events considered in this study, for the period 1953-2006. Month 0 is chosen as the month when N3.4 attains its maximum value for each strong event. Those events with N3.4 higher than $2 \sigma$ (extreme events) are in boldface.

\begin{tabular}{lclc}
\hline $\begin{array}{c}\text { Month 0 of warm } \\
\text { event }\end{array}$ & $\begin{array}{c}\text { N3.4 index } \\
\text { value }\end{array}$ & $\begin{array}{c}\text { Month 0 of cold } \\
\text { event }\end{array}$ & $\begin{array}{c}\text { N3.4 index } \\
\text { value }\end{array}$ \\
\hline January 1958 & 1.91 & November 1955 & $-\mathbf{2 . 1 8}$ \\
December 1963 & 1.1 & November 1964 & -1.19 \\
December 1965 & 1.34 & December 1970 & -1.84 \\
January 1969 & 1.18 & January 1974 & -1.93 \\
December 1972 & $\mathbf{2 . 1 4}$ & January 1976 & -1.85 \\
January 1983 & $\mathbf{2 . 8 5}$ & December 1984 & -1.47 \\
February 1992 & 1.94 & November 1988 & $-\mathbf{2 . 2 4}$ \\
December 1994 & 1.4 & December 1996 & -1.69 \\
November 1997 & $\mathbf{2 . 8}$ & January 2000 & -1.86 \\
November 2002 & 1.75 & & \\
\hline
\end{tabular}

(2004); since no major volcanic eruptions have occurred since 2000, no update of the AOD index has been necessary. The results of the multiple regression fit are then subtracted from the original series, leaving a residual that contains the ENSO signal. The residual series is smoothed to eliminate subseasonal fluctuations by taking a three-point boxcar average. This final product is the series we have used in the analysis of the ENSO signal.

To characterize the ENSO events, the strongest such events in the period 1953-2006 have been chosen according to the monthly mean values of the N3.4. An ENSO event is defined to have taken place whenever N3.4 exceeds 1 standard deviation $\sigma$. Table 1 (leftmost two columns) lists the dates of the warm ENSO events selected and their corresponding N3.4 value. All of them peak in late fall or early winter. The strong El Niño of $1987 / 88$ has not been considered here to avoid misinterpretation of the results, as it has a unique phasing with respect to the seasonal cycle (in 1987 N3.4 index peaked during the summer). Previous studies of the ENSO signal have shown a homogeneous warming throughout the tropical troposphere a few months after the anomalous warming of the SST in the eastern Pacific Ocean (Yulaeva and Wallace 1994; Calvo Fernandez et al. 2004; García-Herrera et al. 2006). In WACCM3 the largest warming in the tropics occurs approximately 2 or 3 months after the maximum of N3.4 (not shown). Therefore, to be concise and maximize the signal, the figures shown in this paper display warm ENSO composites of different variables averaged in time from month 0 to 4 , considering month 0 as the month when the N3.4 reaches its maximum value for each strong warm ENSO event (these "month 0" dates are listed in Table 1); the months selected in this fashion range approximately from December to April (DJFMA). The results and conclusions 
shown here hold when other time averages, such as month $0-3$, or month $1-4$, are considered.

\section{Results}

The composite anomalies of the transformed Eulerian mean (TEM) vertical velocity $\bar{w}^{*}$ for warm ENSO events averaged from month 0 to 4 of the event, as explained above, are shown in Fig. 1a. The anomalies are computed by subtracting the ensemble-mean value of $\bar{w}^{*}$ from its mean value for the set of warm ENSO events. Stippling denotes regions in the latitude-height plane where the results are not significant at the $95 \%$ level using a Monte Carlo test. Random composites of the same number of ENSO cases and the same calendar months as in the actual composites were computed 1000 times and their distribution plotted. The actual composite is considered $95 \%$ significant when its value lies within the $5 \%$ tails $( \pm 1.96$ standard deviations from the mean). The climatological $\bar{w}^{*}$ mean of the extended winter, considering months from December to April, is shown in Fig. $1 \mathrm{~b}$ for comparison with the anomalies. Note that this mean is not calculated over precisely the same period as the ENSO composites, since the latter are referenced to the N3.4 key dates. However, it is a good approximation because ENSO months $0-4$ correspond on average to calendar months December-April, as noted before.

The composites anomalies shown in Fig. 1a indicate anomalous upwelling throughout much of the lowermost tropical stratosphere below $20 \mathrm{~km}$ accompanied by anomalous downwelling in the subtropics. This pattern reveals the upward and downward branches of the anomalous circulation that ENSO generates in the lowermost stratosphere. The largest positive anomalies are located below $18 \mathrm{~km}$ and are shifted toward the NH. This is probably due to the timing of the ENSO events with respect to the seasonal cycle, as warm ENSOs usually peak in boreal winter, when the northern branch of the $\mathrm{BD}$ circulation strengthens. The tropical average $\left(23^{\circ} \mathrm{N}-23^{\circ} \mathrm{S}\right)$ of the vertical velocity anomalies for the ENSO composite $\left\langle\bar{w}^{*}\right\rangle$ is plotted in Fig. 2a (solid line) together with its $2 \sigma$ errors (horizontal bars); it shows maximum upwelling of approximately $2.5 \times 10^{-5} \mathrm{~m} \mathrm{~s}^{-1}$ from 16 to $18 \mathrm{~km}$.
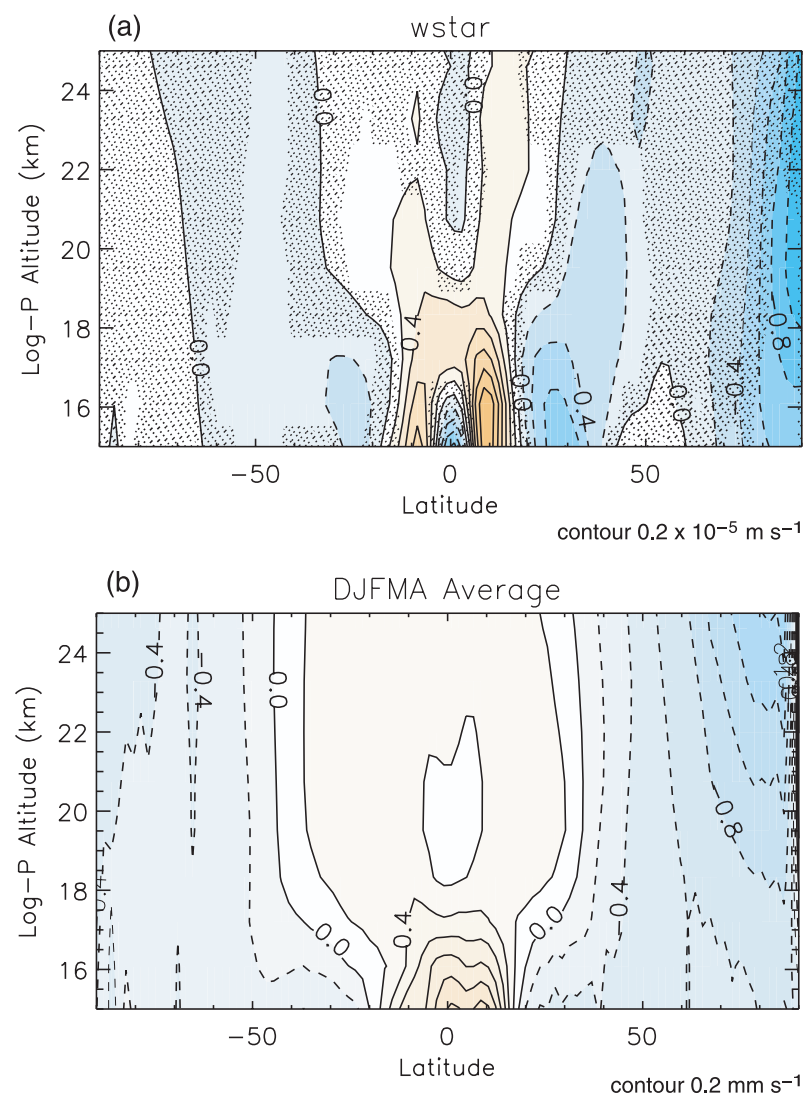

FIG. 1. (a) Cross section (height vs latitude) of the composite anomalies of $\bar{w}^{*}$ (Andrews et al. 1987) for warm ENSO events averaged from month 0 to 4 as explained in the text. Stippled regions are not significant at the $95 \%$ level according to a Monte Carlo test. Contours are drawn every $0.2 \times 10^{-5} \mathrm{~m} \mathrm{~s}^{-1}$. Red denotes positive anomalies; blue denotes negative anomalies. (b) Time mean climatology from December to April of $\bar{w}^{*}$. Contour intervals are $0.2 \mathrm{~mm} \mathrm{~s}^{-1}$. Red denotes positive values (upwelling); blue denotes negative values (downwelling).

The BD circulation is driven by atmospheric waves that propagate from the troposphere and dissipate in the stratosphere, imparting momentum to the mean flow and modulating the stratospheric circulation (Andrews et al. 1987). We have applied the downward control principle (Haynes et al. 1991) to estimate the tropical average of the vertical velocity in terms of parameterized and resolved waves, as in Garcia and Randel (2008):

$$
\left\langle\bar{w}_{\mathrm{DC}}^{*}\right\rangle(z)=\frac{\frac{1}{\rho(z)}\left|\int_{z}^{\infty} \frac{\rho a \cos ^{2} \phi\left[(\rho a \cos \phi)^{-1} \nabla \cdot \mathbf{F}\left(\phi, z^{\prime}\right)\right]+\mathbf{X}\left(\phi, z^{\prime}\right)}{\bar{m}_{\phi}} d z^{\prime}\right|_{-\phi_{0}}^{+\phi_{0}}}{|\sin \phi|_{-\phi_{0}}^{+\phi_{0}}}
$$

where $\mathbf{F}$ is the Eliassen-Palm (EP) flux due to waves explicitly resolved in the model and $\mathbf{X}$ is the eddy momentum flux divergence due to (parameterized) gravity waves; $\phi$ is the latitude, $m_{\phi}$ is the meridional 
(a)

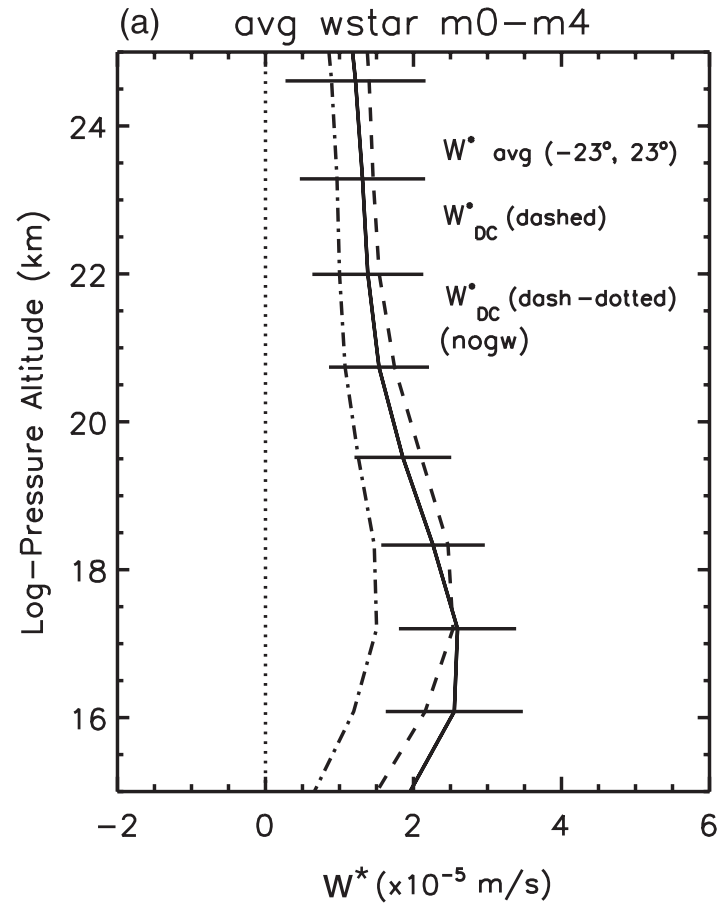

(b)

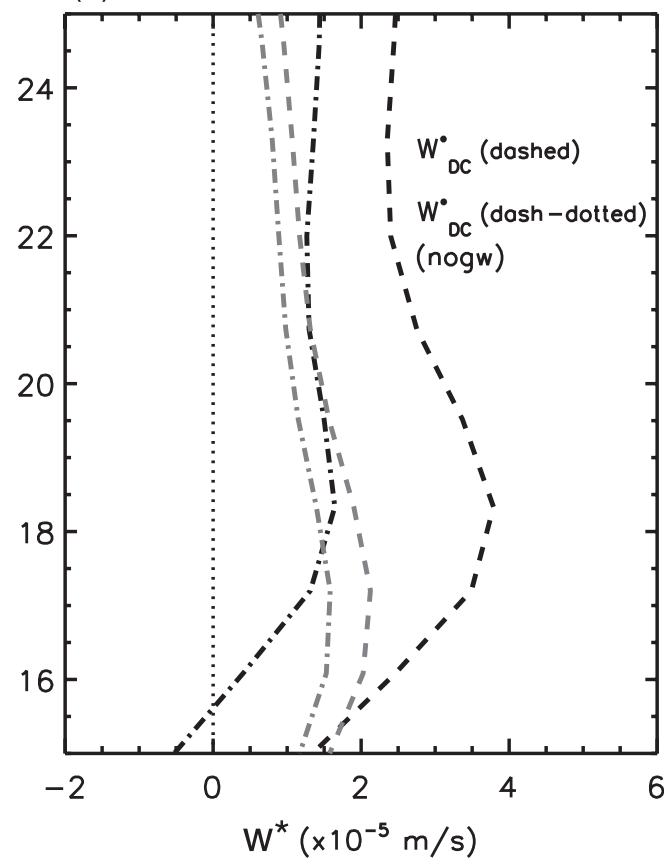

FIG. 2. (a) Composite of $\bar{w}^{*}$ averaged over the tropical region $\left( \pm 23^{\circ}\right)$ for warm ENSO events averaged from month 0 to 4 of the event. The horizontal lines represent the $2 \sigma$ confidence limits. The solid line denotes the actual value calculated from the model output for $\bar{w}^{*}$; the dashed line is computed via the downward control principle using parameterized and resolved wave forcing. The dashed-dotted curve omits the contribution of parameterized waves. (b) As in (a), but for the downward control vertical velocity computed using the forcing due to all waves (dashed lines) and forcing due to resolved waves only (dashed-dotted lines). Two sets of lines are shown for each case: the black lines are the result for the extreme ENSO composite, while the gray lines denote the standard ENSO composite. See text for details.

gradient of zonal-mean potential vorticity, $z$ is the logpressure altitude, $a$ is the radius of the earth, $\rho$ is the logpressure density, and $\pm \phi_{0}$ is the range of latitude over which the tropical average is computed.

Equation (1) can be used to investigate the role of different waves in the acceleration of the BD circulation during warm ENSO events. The dashed curve in Fig. 2a (left) shows the composite tropical upwelling anomaly for El Niño events (averaged over months $0-4$ of the events and over $23^{\circ} \mathrm{N}-23^{\circ} \mathrm{S}$ ) computed using the downward control principle $\left\langle\bar{w}_{\mathrm{DC}}^{*}\right\rangle$. The latitude range $23^{\circ} \mathrm{N}-$ $23^{\circ} \mathrm{S}$ has been selected for the tropical average because it encompasses the region of stratospheric upwelling in WACCM3 while still allowing accurate evaluation of the integrand in Eq. (1) during ENSO months (mainly boreal winter) along constant latitudes. That is, at $23^{\circ} \mathrm{N}$ and $23^{\circ} \mathrm{S}$ contours of constant mean angular momentum are almost parallel to latitude lines, so the integrand of Eq. (1) can be evaluated at constant latitude without introducing significant errors. The good agreement between $\left\langle\bar{w}^{*}\right\rangle$ and $\left\langle\bar{w}_{\mathrm{DC}}^{*}\right\rangle$ in Fig. 2a confirms that the constantlatitude approximation used here is indeed valid.
The role of resolved and parameterized waves can be inferred by comparing the dashed and dashed-dotted curves in Fig. 2a, where the dashed-dotted curve represents the composite anomaly of $\left\langle\bar{w}_{\mathrm{DC}}^{*}\right\rangle$ computed taking into account only waves resolved by the model, and excluding parameterized gravity waves. The difference between the dashed and dashed-dotted lines corresponds to the contribution of parameterized waves. In the lowermost stratosphere, both resolved and parameterized waves are important contributors in forcing the acceleration of the $\mathrm{BD}$ circulation, with parameterized gravity wave driving accounting for between one-third and one-half of the total acceleration. This result differs from that found by Garcia and Randel (2008) in their study of the acceleration of the BD circulation under increasing concentrations of greenhouse gases. There, anomalous forcing by (resolved) Rossby waves in the subtropics was the major contributor to the acceleration of the $\mathrm{BD}$ circulation, while the role of parameterized waves was minor. This is not the case during warm ENSO events simulated with WACCM. 
The influence of the parameterized gravity waves is even more noticeable when only the strongest warm ENSO events are considered. The right panel of Fig. 2 shows results for $\left\langle\bar{w}_{\mathrm{DC}}^{*}\right\rangle$ in two subgroups of warm ENSO events: Black lines denote the composite anomalies of $\left\langle\bar{w}_{\mathrm{DC}}^{*}\right\rangle$ for the strongest warm ENSO events of the period (those for which N3.4 is higher than 2 standard deviations, which are highlighted in bold in Table 1 and hereafter are called extreme warm ENSO events). Gray lines are used for the remaining ENSO events, with $\mathrm{N} 3.4$ between 1 and 2 standard deviations (hereafter referred to as standard warm ENSO events). The tropical upwelling in the lower stratosphere (below $20 \mathrm{~km}$ ) is much larger in the case of extreme ENSO events, as seen from the comparison between black and gray dashed lines $\left(3.75 \mathrm{~m} \mathrm{~s}^{-1}\right.$ versus $\left.1.6 \times 10^{-5} \mathrm{~m} \mathrm{~s}^{-1}\right)$. In addition, its maximum value is observed at higher altitudes (18.5 km versus $17 \mathrm{~km}$ for the standard ENSO events). It is evident from the figure that this is the result of the dominant influence of the parameterized waves. While for the standard case (gray curves), parameterized gravity waves explain less than one-third of the total tropical upwelling, in the case of extreme ENSO events the gravity waves account for almost two-thirds of the total $\left\langle\bar{w}_{\mathrm{DC}}^{*}\right\rangle$ anomaly (cf. the differences between dashed and dashed-dotted curves). Note also that resolved waves actually produce slight anomalous downwelling (weaker upwelling) below $16 \mathrm{~km}$ in the case of extreme ENSO events, and gravity waves are essential for producing the enhanced upwelling observed in the tropical region in Fig. 2a. Analogous results are obtained when different thresholds (between 1.5 and 2 standard deviations) are used for defining the extreme and standard ENSO events. Expanding the latitude range used to compute the tropical average $\left\langle\bar{w}_{\mathrm{DC}}^{*}\right\rangle$ to $\pm 26^{\circ}$ increases slightly the influence of gravity waves in forcing the tropical upwelling but does not materially alter any of the foregoing conclusions.

The spatial distribution of the anomalous wave forcing is shown in Fig. 3. Figure 3a shows the anomalous forcing due to both resolved and parameterized waves. The downward control principle, per Eq. (1), establishes that the tropical average upwelling is determined by the wave forcing at the edge of the tropical region (red lines in Fig. 3). Most of the anomalous wave forcing observed during warm ENSO events comes from the NH subtropics between 18 and $22 \mathrm{~km}$. In the $\mathrm{SH}$, a smaller contribution is observed at lower altitudes between 17 and $20 \mathrm{~km}$. Figure $3 \mathrm{~b}$ shows the anomalous forcing due exclusively to resolved waves by the model, diagnosed by the EP flux divergence. The forcing due to gravity waves can be then deduced as the difference between both panels and is shown in Fig. 3c. In the SH the total
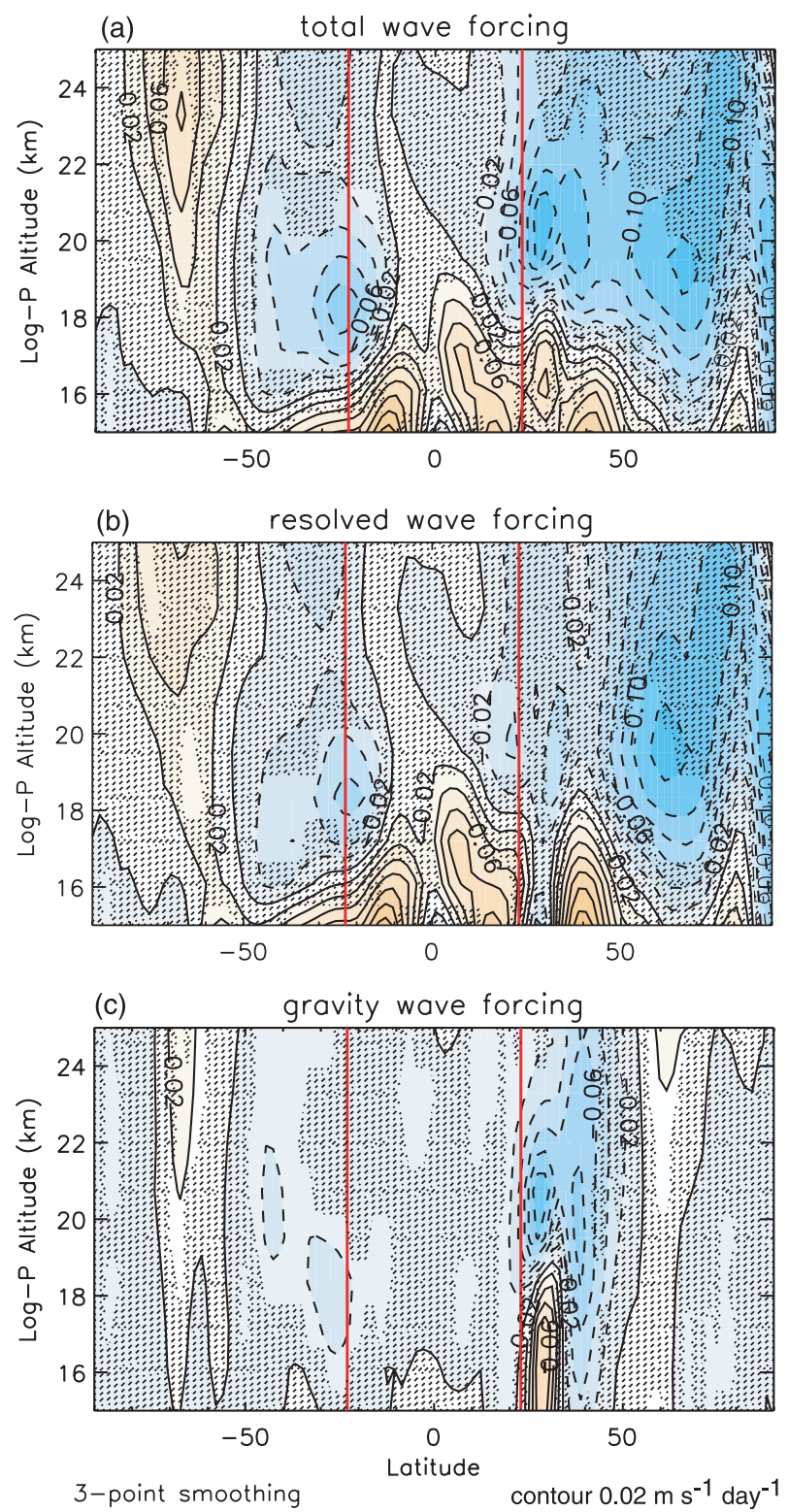

FIG. 3. As in Fig. 1a, but for anomalies in (a) total wave forcing including both resolved and parameterized waves, (b) resolved Rossby wave forcing (EP flux divergence), and (c) parameterized gravity wave drag. Contour intervals are $0.02 \mathrm{~m} \mathrm{~s}^{-1}$ day $^{-1}$. Red lines denote the latitudes $\left( \pm 23^{\circ}\right)$ selected to compute the tropical average in Fig. 2 and to apply the downward control principle.

wave forcing is comparable to the resolved wave forcing. However, the largest difference appears in the $\mathrm{NH}$ subtropics between 18 and $22 \mathrm{~km}$ and is due to the gravity wave drag (Fig. 3c). A decomposition of the parameterized wave forcing into orographic and nonorographic components (not shown) revealed that the orographic component accounts for almost all the anomaly in gravity wave drag, the nonorographic contribution being insignificant. 


\section{Discussion}

We have shown that the tropical upwelling is enhanced in the lowermost tropical stratosphere, below $20 \mathrm{~km}$, during warm ENSO events, mainly because of anomalous orographic gravity wave forcing in the $\mathrm{NH}$ subtropics during the most extreme warm ENSO events. It remains to be explained why the gravity wave forcing intensifies in that region. Many studies have shown that warm ENSO events generate a large anomalous zonal warming in the tropical troposphere approximately 3 months after the maximum of Niño-3.4 (e.g., Yulaeva and Wallace 1994; Calvo Fernandez et al. 2004), which is also obtained in our simulations. Thus, the meridional gradient of temperature intensifies during warm ENSO events, strengthening the jet streams in the subtropics. Composite anomalies of zonal-mean temperature and zonal wind during the warm ENSO events are shown in Fig. 4. Anomalous warming in the troposphere and cooling in the stratosphere is calculated in the tropical regions together with an intensification of the subtropical jets in the UTLS. The strongest intensification of the subtropical jet occurs in the NH because the warm ENSO events peak in boreal winter. These anomalies are even stronger when the extreme ENSO events are considered, with the wind anomalies in the NH subtropics reaching up to $5 \mathrm{~m} \mathrm{~s}^{-1}$ (not shown). Thus, the stronger winds in the UTLS in the northern subtropics favor the dissipation of the gravity waves at higher altitudes and intensify the gravity wave drag, which is proportional to the intensity of the zonal-mean zonal wind (e.g., Andrews et al. 1987). The larger anomalies in orographic gravity wave forcing then drive the enhancement of the tropical upwelling in the lowermost stratosphere. It is worth noting again that most of the ENSO signal in the upwelling in the lowermost tropical stratosphere is obtained from anomalous gravity wave forcing during the most extreme warm ENSO events.

We also investigated the effect of cold ENSO events in the tropical UTLS (the two rightmost columns of Table 1 list the cold ENSO events selected). A significant signal similar to that obtained during warm ENSO cases is observed but is of opposite sign, which adds confidence to the results and mechanisms discussed here. During cold ENSO events, anomalous downwelling (weaker upwelling compared with the climatology; see Fig. 1b) is observed in the tropics below $18 \mathrm{~km}$, with a similar pattern to the warm ENSO case. The anomalies, however, are weaker and the tropical upwelling averaged between $\pm 23^{\circ}$ reaches $-1.75 \times 10^{-5} \mathrm{~m} \mathrm{~s}^{-1}$ versus $2.5 \times 10^{-5} \mathrm{~m} \mathrm{~s}^{-1}$ in the warm ENSO composite. Analysis via the downward control principle indicates that parameterized orographic gravity waves play a
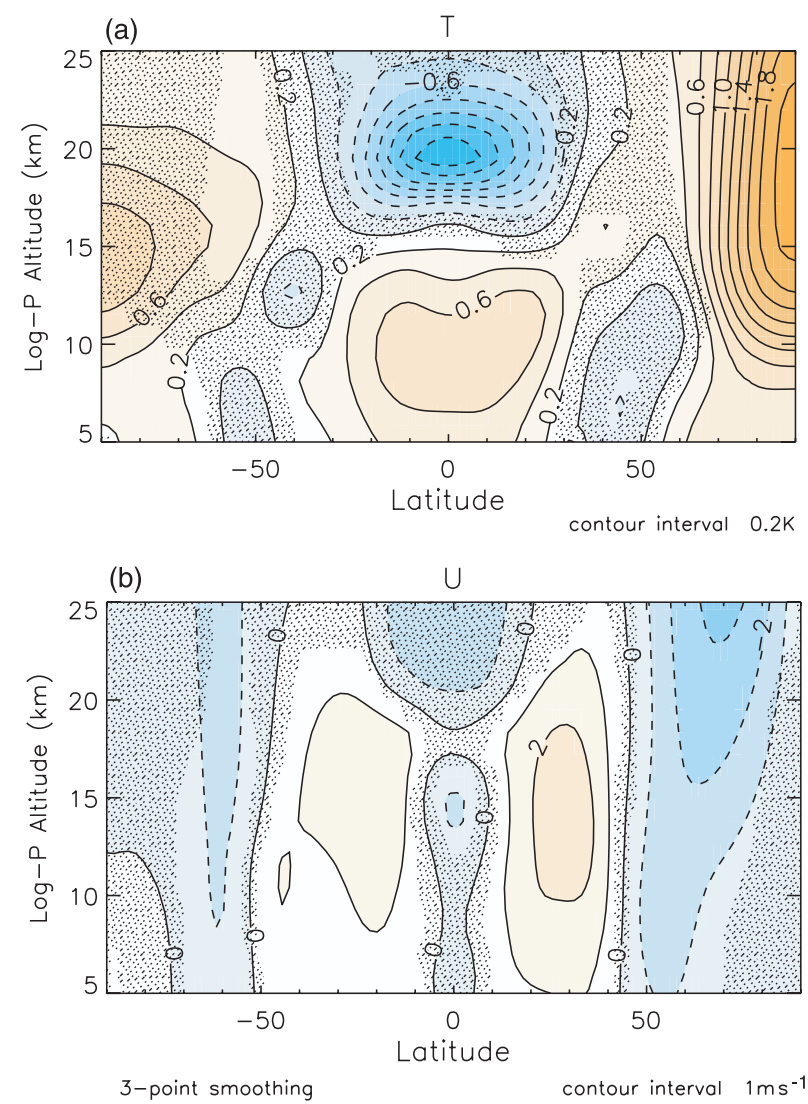

FIG. 4. As in Fig. 1a, but for (a) zonal-mean temperature and (b) zonal wind anomalies for the warm ENSO events. Contours are drawn every $0.2 \mathrm{~K}$ for temperature and $1 \mathrm{~m} \mathrm{~s}^{-1}$ for zonal winds.

leading role in forcing the cold ENSO anomalies, as in the warm ENSO case. Anomalous cooling in the tropical troposphere and anomalous warming in the tropical lower stratosphere are obtained during cold ENSO events, which leads to weaker tropospheric jets in the subtropics, especially in the NH. This weakening favors the dissipation of the gravity waves at lower altitudes and the generation of anomalous positive gravity wave drag at higher altitudes (the opposite of the warm ENSO case), which ultimately forces negative anomalies in tropical upwelling (weaker tropical upwelling than in the climatology). To illustrate this, the results of the downward control principle analysis and the composite of zonalmean temperature are shown in Figs. 5 and 6, which are analogous to Figs. 2a and 4a of the warm ENSO case.

The anomalous circulation induced by ENSO in the tropical lower stratosphere produces a distinct signal in the distribution of trace gases in that region. Figure 7 shows warm and cold ENSO composite anomalies for ozone in percentage change with respect to the long-term mean from DJFMA, which encompasses approximately the same months as in the ENSO composite because 


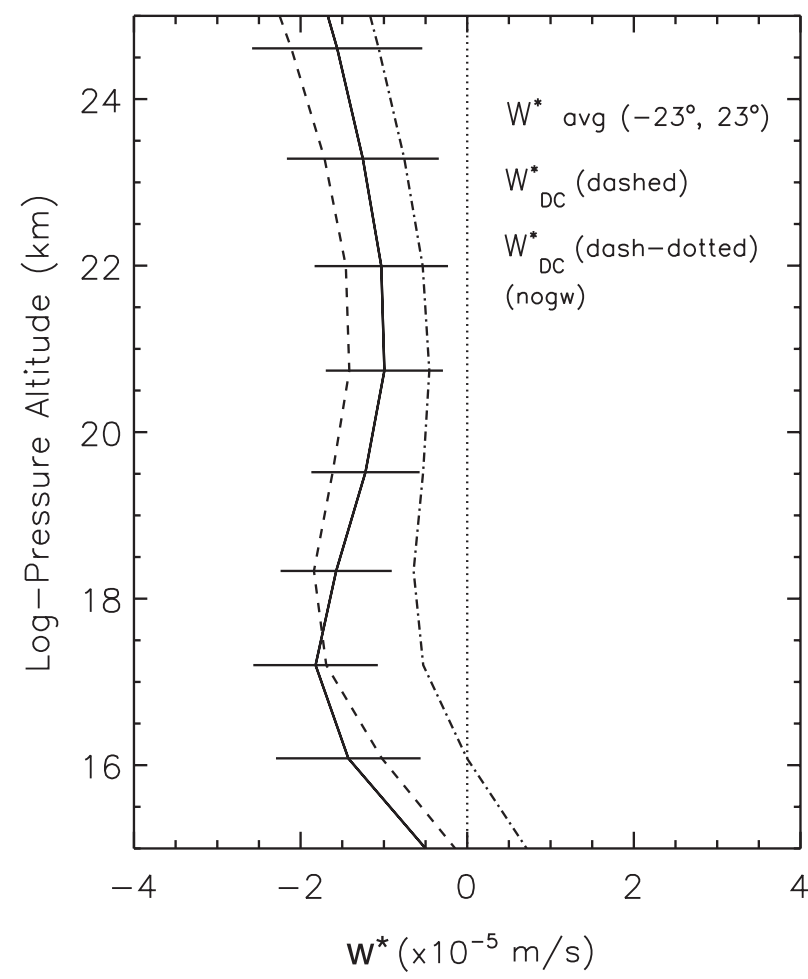

FIG. 5. As in Fig. 2a, but for cold ENSO events.

ENSO events peak in December-January. Hardly any differences are found when the long-term winter mean December-March is used. Negative values are observed above the tropical tropopause as a result of enhanced upwelling during warm ENSO events. During cold ENSO events, the anomaly pattern is similar but with reversed sign. The ENSO signal in ozone (Fig. 7) as well as the signal in temperature (Figs. 4a and 6) and tropical upwelling (Figs. 2a and 5a, solid line) obtained here confirm the relationship found by Marsh and Garcia (2007) in their correlation analysis between ENSO and these variables in the lower stratosphere. Our patterns are also very similar to those shown in Randel et al. (2009) even though our methodology is different from that used by these authors. Randel et al. included an ENSO predictor in a multiple linear regression analysis to isolate the ENSO signal, whereas here we have composited ENSO events using the N3.4 index after removing other sources of variability from WACCM3 output. Both methods lead to remarkably similar spatial patterns, although our composite analysis produces slightly higher amplitudes. This may be due to the fact that the composite methodology emphasizes the ENSO events selected (i.e., periods when N3.4 is at least 1 standard deviation above the mean).

ENSO events in WACCM are also associated with anomalies in the distribution of water vapor, both in the troposphere and the stratosphere. Figure 8a shows

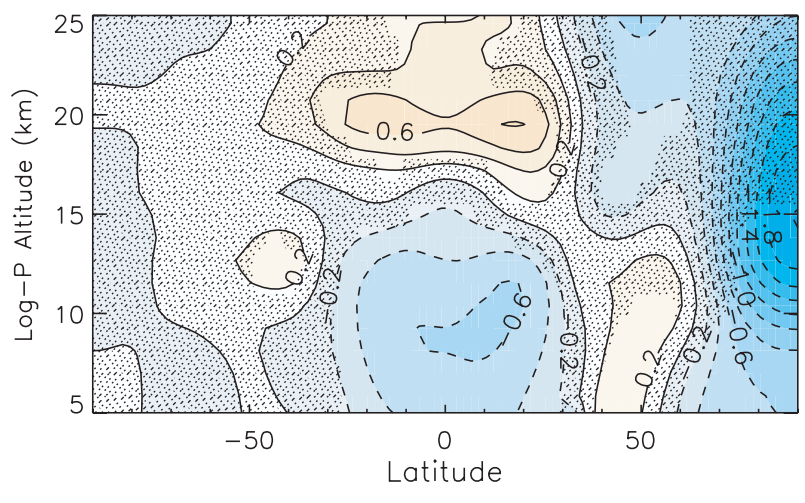

3-point smoothing

contour interval $0.2 \mathrm{~K}$

FIG. 6. As in Fig. 4a, but for cold ENSO events.

the temporal evolution (from month -12 to +36 ) of the composite of water vapor anomalies during warm ENSO events. The behavior is morphologically very similar to that shown by Garcia et al. (2007, their Fig. 17), who used a version of WACCM that did not include variability due to the QBO or to volcanic eruptions. (Note, however, that Garcia et al. showed the correlation between N3.4 and water vapor, whereas Fig. 7a shows composite
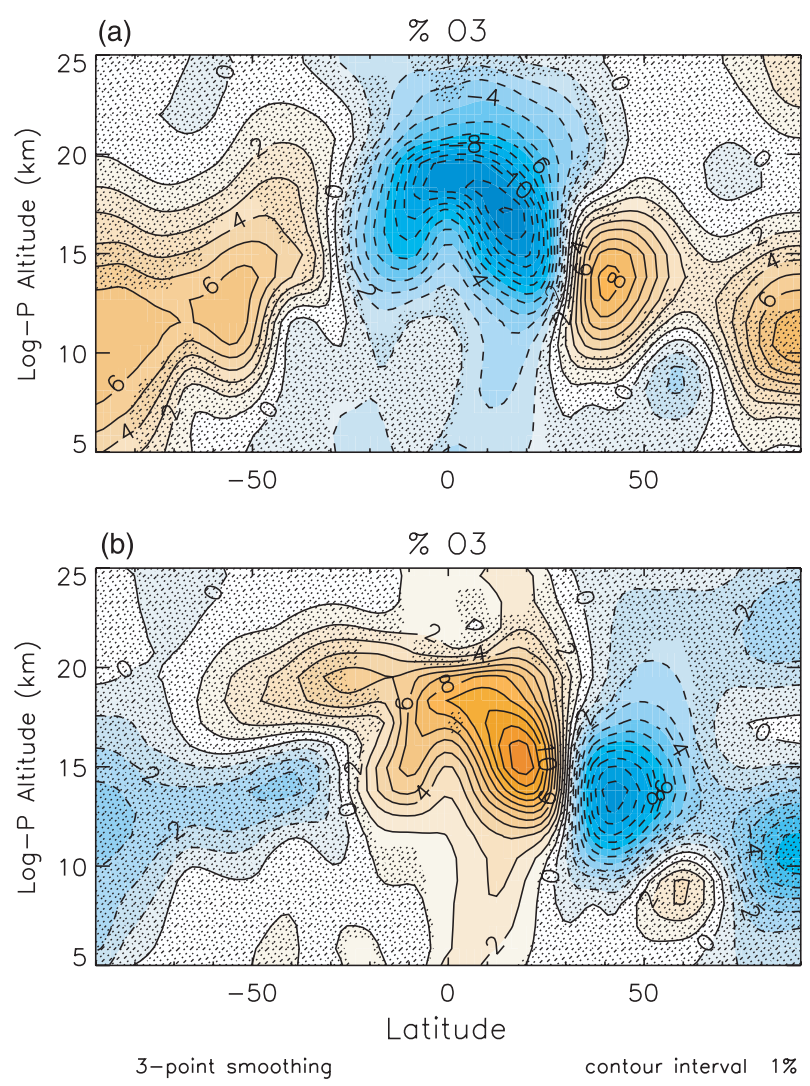

FIG. 7. As in Fig. 1a, but for the percentage change in ozone anomalies with respect to the DJFMA value for (a) warm and (b) cold ENSO events. Contours are drawn every $1 \%$. 


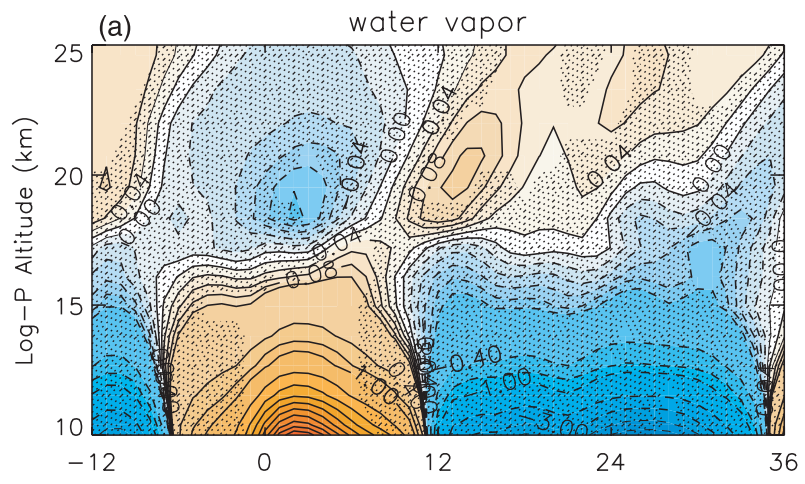

(b)

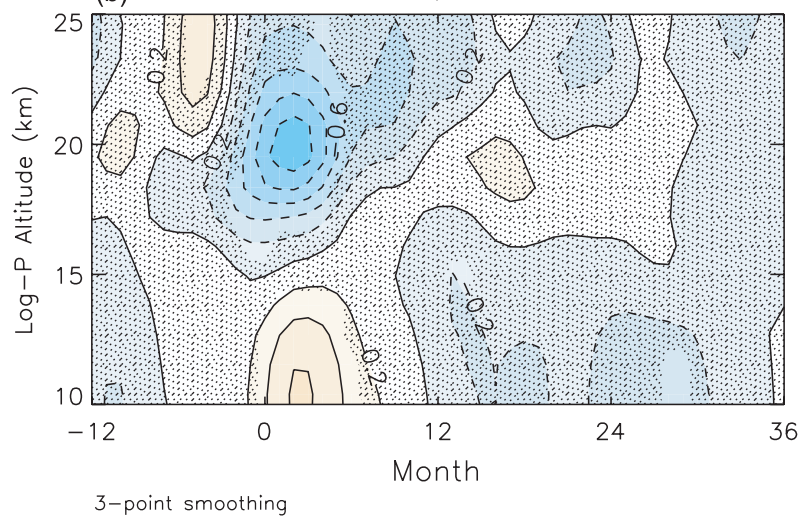

FIG. 8. Altitude-time composite of anomalies in (a) water vapor and (b) zonal mean temperature averaged between $\pm 30^{\circ}$ during warm ENSO events. Stippled regions are not significant at the $95 \%$ level according to a Monte Carlo test. Red denotes positive anomalies and blue denotes negative anomalies. Contour intervals are $0.02 \mathrm{ppm}$ for water vapor anomalies between 0 and $0.1,0.3 \mathrm{ppm}$ between 0.1 and 1 , and $1 \mathrm{ppm}$ for anomalies larger than $1(0, \pm 0.02$, $\pm 0.04, \pm 0.06, \pm 0.08, \pm 0.1, \pm 0.4, \pm 0.7, \pm 1, \pm 2 \ldots)$. The contour interval for temperature is $0.2 \mathrm{~K}$.

anomalies). In both Garcia et al.'s study and the present one warm ENSO events are associated with enhanced water vapor in the troposphere and reduced water vapor in the lower stratosphere. The negative water vapor anomaly in the stratosphere during the peak ENSO months presumably follows from the colder temperatures in the lowermost stratosphere that accompany warm ENSO events, which are shown in Fig. 8b. However, in the year following the peak of the warm ENSO event, the water vapor anomaly in the stratosphere becomes positive and remains that way for 1-2 years thereafter. In contrast to the drying observed in the stratosphere during the first year of the warm ENSO event, this delayed moistening does not seem to be related to anomalies in the cold point temperature, as the temperature composite shows hardly any signal in the stratosphere after month 6 of the warm ENSO peak (see Fig. 8b). The magnitude of the positive water vapor anomalies in the tropical stratosphere is on the order of $\pm 3 \%$ to $4 \%$ of local values averaged over $\pm 30^{\circ}$ (not shown), similar to the anomalies obtained in the previous version of the model discussed above. During cold ENSO events, however, no significant water vapor anomalies are observed above the tropopause in any month (not shown). In short, warm ENSO events in WACCM are associated with a delayed moistening of the tropical stratosphere, which, as argued by Garcia et al. (2007), constitutes a source of significant low-frequency variability and complicates the estimation of water vapor trends for short time series of water vapor.

The mechanism that gives to the delayed moistening of the stratosphere after warm ENSO events is not well understood. Nevertheless, there is some indication that, in WACCM, it is related to the injection of water vapor into the lowermost stratosphere by the circulation associated with the northern summer monsoon (cf. Park et al. 2004). Figure 9 shows the latitude-time distribution of the composite water vapor anomalies during warm ENSO events at two different levels, 100 and $61 \mathrm{hPa}$, to illustrate the upward propagation of the water vapor anomalies. Positive anomalies in water vapor are present throughout the tropical troposphere all the way up to $100 \mathrm{hPa}$, as seen in the top panel of Fig. 9. The anomalies extend to middle latitudes (where the $100-\mathrm{hPa}$ level is actually in the stratosphere) starting approximately half of a year following the maximum in N3.4, which corresponds to northern summer, and thus are consistent with the timing of the Northern Hemisphere monsoon. At $61 \mathrm{hPa}$ (bottom panel of Fig. 9), water vapor anomalies are actually negative throughout much of the year following the peak N3.4 but become positive at a lag of some 8-9 months, suggesting that they arise from upward and equatorward propagation of the subtropical anomalies present at $100 \mathrm{hPa}$.

\section{Conclusions}

We have explored the mechanism that produces accelerations of the $\mathrm{BD}$ circulation in the lowermost tropical stratosphere during ENSO events in the Whole Atmosphere Community Climate Model. The strengthening of the tropical upwelling during warm ENSO events and its weakening during cold events leads to distinct signals in temperature and ozone that are in excellent agreement with a recent analysis of observations by Randel et al. (2009). The mechanism involves enhanced wave driving of the tropical upwelling both by parameterized gravity waves and explicitly resolved Rossby waves during warm events and by reduced wave driving during cold events. In this sense, the mechanism is similar to that found to operate under increasing GHG 

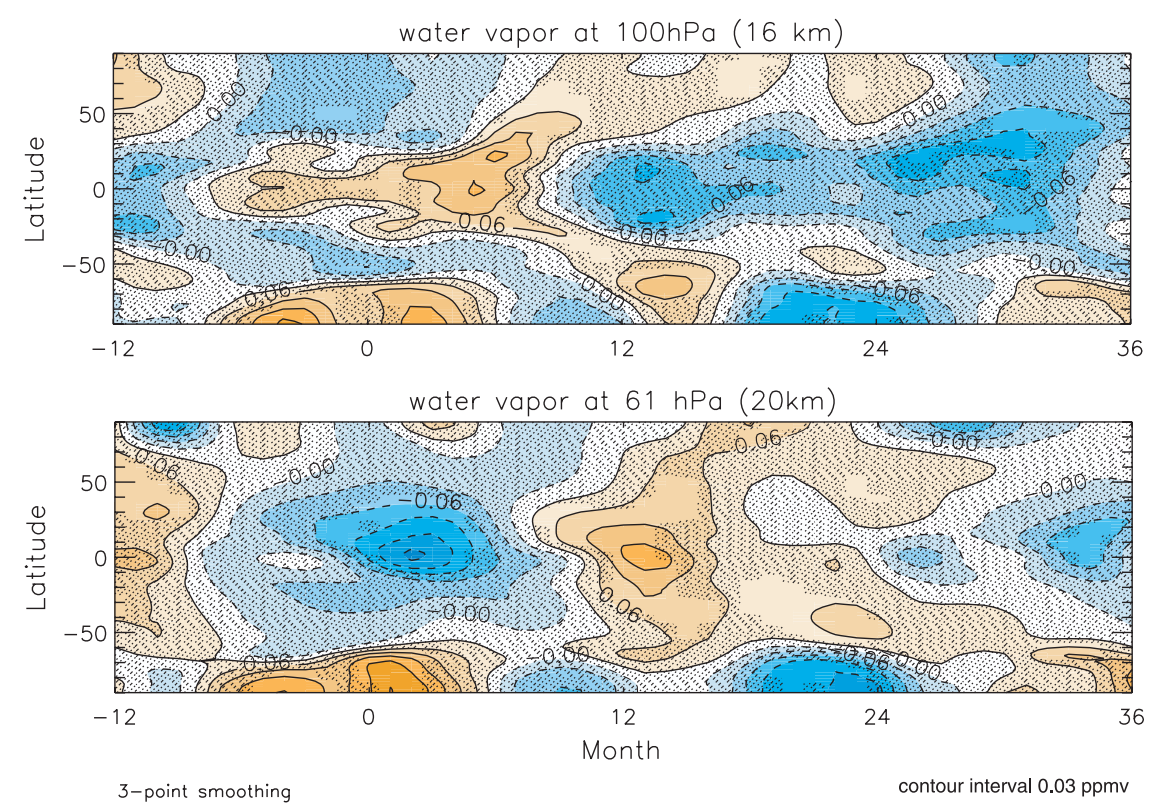

FIG. 9. As in Fig. 8, but for the latitude-time composites of water vapor anomalies during warm ENSO events at (top) 100 and (bottom) $61 \mathrm{hPa}$. Contour interval is $0.03 \mathrm{ppm}$.

concentrations by Garcia and Randel (2008). However, contrary to the findings of Garcia and Randel (2008), during ENSO events enhanced wave driving by parameterized orographic gravity waves is found to be generally more important than driving due to resolved waves.

The response of the tropical upwelling to ENSO events appears to be a characteristic feature of WACCM simulations. Similar results are found with the present model as with a previous version (Garcia et al. 2007; Marsh and Garcia 2007) that did not include variability associated with the QBO or with volcanic eruptions. This suggests that the effect of ENSO is both robust and independent of other mechanisms that can perturb the circulation of the lower stratosphere. An interesting additional result is a delayed positive anomaly in tropical stratospheric water vapor for warm events, obtained with both the present model and with the model used by Garcia et al. (2007), which begins approximately one year following ENSO events and lasts for an additional 1-2 years. To our knowledge, this behavior has not been documented in observations but has the potential to introduce lowfrequency variability in water vapor time series that could confound the estimation of secular trends. This topic, as well with independent studies of the response to ENSO using other chemistry-climate models, bears further investigation in order to elucidate the generality of the mechanisms discussed in this study.

Acknowledgments. N. Calvo was supported by the Spanish Ministry of Education and Science, the Fulbright
Commission in Spain, and the visitors' program of the Atmospheric Chemistry Division at the National Center for Atmospheric Research (NCAR). She was also partially supported by the Spanish Ministry of Education and Sciences under Contract CGL2007-65891-C05-02/ CLI (TRODIM project). WACCM calculations presented in this paper were carried out at NCAR; at the NASA Advanced Supercomputing Division, Ames Research Center; and at the Oak Ridge Leadership Computing Facility of the U.S. Department of Energy.

\section{REFERENCES}

Andrews, D. G., J. R. Holton, and C. B. Leovy, 1987: Middle Atmosphere Dynamics. Elsevier, 489 pp.

Calvo Fernandez, N., R. García, R. García Herrera, D. Gallego Puyol, L. Gimeno Presa, E. Hernández Martín, and P. Ribera Rodríguez, 2004: Analysis of the ENSO signal in tropospheric and stratospheric temperatures observed by MSU, 1979-2000. J. Climate, 17, 3934-3946.

Garcia, R. R., and W. J. Randel, 2008: Acceleration of the BrewerDobson circulation due to increases in greenhouse gases. J. Atmos. Sci., 65, 2731-2739.

_ D. R. Marsh, D. E. Kinnison, B. A. Boville, and F. Sassi, 2007: Simulations of secular trends in the middle atmosphere, 19502003. J. Geophys. Res., 112, D09301, doi:10.1029/2006JD007485.

García-Herrera, R., N. Calvo, R. R. Garcia, and M. A. Giorgetta, 2006: Propagation of ENSO temperature signals into the middle atmosphere: A comparison of two general circulation models and ERA-40 reanalysis data. J. Geophys. Res., 111, D06101, doi:10.1029/2005JD006061.

Haynes, P. H., C. J. Marks, M. E. McIntyre, T. G. Sheperd, and K. P. Shine, 1991: On the "downward control" of extratropical 
diabatic circulations by eddy-induced mean zonal forces. J. Atmos. Sci., 48, 651-678.

Manzini, E., M. A. Giorgetta, M. Esch, L. Kornblueh, and E. Roeckner, 2006: The influence of sea surface temperatures on the northern winter stratosphere: Ensemble simulations with the MAECHAM5 model. J. Climate, 19, 3863-3881.

Marsh, D. R., and R. R. Garcia, 2007: Attribution of decadal variability in lower-stratospheric tropical ozone. Geophys. Res. Lett., 34, L21807, doi:10.1029/2007GL030935.

Matthes, K., U. Langematz, L. L. Gray, K. Kodera, and K. Labitzke, 2004: Improved 11-year solar signal in the Freie Universität Berlin Climate Middle Atmosphere Model (FUB-CMAM). J. Geophys. Res., 109, D06101, doi:10.1029/2003JD004012.

McFarlane, N. A., 1987: The effect of orographically excited gravity wave drag on the general circulation of the lower stratosphere and troposphere. J. Atmos. Sci., 44, 1775-1800.

Park, M., W. J. Randel, D. E. Kinnison, R. R. Garcia, and W. Choi, 2004: Seasonal variation of methane, water vapor, and nitrogen oxides near the tropopause: Satellite observations and model simulations. J. Geophys. Res., 109, D03302, doi:10.1029/ 2003JD003706.
Randel, W. J., and F. Wu, 1996: Isolation of the ozone QBO in SAGE II data by singular-value decomposition. J. Atmos. Sci., 53, 2546-2559.

_ - R. R. Garcia, N. Calvo, and D. Marsh, 2009: ENSO influence on zonal mean temperature and ozone in the tropical lower stratosphere. J. Geophys. Res., 36, L15822, doi:10.1029/ 2009 GL039343.

Richter, J. H., F. Sassi, and R. R. Garcia, 2010: Toward a physically based gravity wave source parameterization in a general circulation model. J. Atmos. Sci., 67, 136-156.

Sassi, F., D. E. Kinnison, B. A. Boville, R. R. Garcia, and R. R. Roble, 2004: Effect of El Niño-Southern Oscillation on the dynamical, thermal, and chemical structure of the middle atmosphere. J. Geophys. Res., 109, D17108, doi:10.1029/2003JD004434.

Tilmes, S., R. R. Garcia, D. E. Kinnison, A. Gettelman, and P. J. Rasch, 2009: Impact of geoengineered aerosols on the troposphere and stratosphere. J. Geophys. Res., 114, D12305, doi:10.1029/2008JD011420.

Yulaeva, E., and J. M. Wallace, 1994: The signature of ENSO in global temperature and precipitation fields derived from the Microwave Sounding Unit. J. Climate, 7, 1719-1736. 